\title{
Sustainable cities: paths taken in Brazil
}

\author{
L. Brazil, D. Vivas, M. A. Sarmento \& O. Longo \\ Department of Engineering, Federal Fluminense University, Brazil
}

\begin{abstract}
This paper is based on partial results obtained from an exploratory research project carried out in Rio de Janeiro's metropolitan area (RMRJ). It aims to illustrate how Brazil has been coping with unsustainability issues in urban areas. We focus on pointing out the achievements obtained so far, as well as new possibilities resulting from this research.
\end{abstract}

Keywords: sustainable cities, unsustainability.

\section{Introduction}

The project entitled Sustainable cities: paths taken in Brazil has been carried out by participants of the HIDROUFF Research Group, under the line of research named Environment, Sustainability and Social Responsibility. Its overall goal consists in developing partnership strategies among institutions within the Federal Fluminense University (UFF), with the aim strengthening their developed expertise and transforming them into sustainability-oriented sites, under an amplified, progressive perspective.

Sustainability is firstly conceived as a pragmatic process of sustainable development. The second concept introduces new dimensions in order to promote its understanding beyond economic and environmental issues, thus allowing sustainability to be considered in accordance with the particularities of each country or region. In Brazil, for example, this last concept has contributed to sustainability being conceive from ethnical and racial perspectives, bearing in mind the inequalities still faced by afro-descendants.

The main stages of the research were the following: development of the theoretical-conceptual framework by using the many authors as reference [1-4] compilation and analysis of reference documents related to sustainability in Brazilian urban areas published between 1980 and 2010; interviews with staff from government agencies identification of key people or groups involved in the 
promotion of sustainability in the urban environment; identification of sustainability projects; analysis of projects so as to identify the corresponding sustainability dimensions with regard to the concepts of amplified and progressive sustainability (defined in Section 3); development of partnership strategies; and consolidation of sustainability-orientated units.

The first stages of the research consisted in the identification of the main documents published in Brazil that have been the basis for sustainability acts: the Brazilian Federal Constitution (1988), the Brazilian Agenda 21, the City Statute, and the Sustainable Cities Platform. In addition, these stages showed that the key roles in sustainability issues are played by universities, companies, and nongovernmental organizations (NGOs). Universities are acting towards widening their range of courses, carrying out research, developing projects, and, in particular, realizing outreach activities; companies take part by adopting the concept of Social Responsibility; and NGOs by means of projects. Under these initiatives, the concept of amplified sustainability must be highlighted, and can be described as consisting of:

- Environmental sustainability: refers to the capacity of the associated ecosystems to absorb and recover from the interferences deriving from human activity, thus creating a balance between the emission and/or residue production rates and the absorption and/or regeneration rates of the natural resource base.

- $\quad$ Ecological sustainability: refers to the physical base of the ecosystem growing process and focuses on the maintenance and the rational use of the available natural resources that are employed for productive activities.

- Cultural sustainability: can be understood as the need to maintain the diversity of cultures, beliefs, and practices which exist globally or in the country and/or region and constitute the identity of people over time.

- Social sustainability: consists in promoting a better quality of life and reducing social exclusion by means of public policies promoting redistributive justice.

- $\quad$ Political sustainability: refers to the achievement of plain citizenship of individuals by strengthening democratic mechanisms for the formulation and implementation of public policies on a global scale, in addition to government and governability on local, national, and global scales.

- Institutional sustainability: regards the need for creating and strengthening institutional engineering whose design and apparatus already bear in mind sustainability criteria [5].

This paper covers more specifically the documents relevant to sustainability whereas the two forthcoming papers will present the actions in detail. Firstly, we describe the process in which unsustainability scenarios are shaped, succinctly pointing out related facts of the Brazilian urbanization history in the $20^{\text {th }}$ century. Such facts were not chosen at random, but based on their significance for the configuration of the urban environment. Next, the documents published in Brazil are presented, together with their main guidelines. And finally, conclusions are shared in the last section. 


\section{Unsustainability scenarios in the urban environment: some facts}

"The most noticeable characteristic of Brazilian urbanization resides in its clear dissociation from poverty. Throughout this process, the spatial dynamics of the city edges has segregated the poor, in addition to expressing the most noticeable aspects of the development of capitalism in the country" [6].

Building sustainable cities has become one of today's most challenging tasks, given the fact that almost half of world's population (47\%) lives in urban areas, and a considerable percentage of people live under unsustainable conditions, mainly with regard to social and environmental dimensions. Such conditions may be labelled as unsustainable seeing as they do not promote inclusion, prosperity, creativity, education, health, democracy, a good quality of life, and, hence, do not allow the participation of the general public in all the aspects associated with public issues.

Current studies estimate a yearly urban population growth of about $2 \%$ between 2000 and 2015, and Brazilian cities are no exception to this global trend. According to the 2010 census, 85\% of Brazil's population live in urban areas. This percentage may increase in coming decades

In this urban scenario, several types of cities could be identified. In this paper, cities were classified into 5 types, according to their location in relation to the downtown area: central cities, suburb cities, peripheral cities, countryside cities, and, finally, risk cities.

Inside central cities, so-called gated communities keep themselves isolated from communitarian life, with private access to green areas and fountains, areas that are crucial for the so-called urban-environmental sustainability. Peripheral cities are often characterized by poor conditions of health, housing, leisure and transportation, as well as spatial segregation, all of which contribute to the stigmatization of the population and ultimately compromise the principle of human dignity. In risk cities, moreover, vulnerable conditions and recurrent hazards frequently results in landslides, floods, and diseases.

The Brazilian urbanization process started in the first decades of the $20^{\text {th }}$ century, after the Pereira Passos reform. This reform caused a change in urban spatiality and can be considered as the trigger point of a process that would intensify during the course o the following decades. Also, it defined new settlements for each one of the social groups that, until then, shared a single city, the central area of the Federal District at that time. From this process three distinct cities came out: the European, the Quilombola, and the Suburban. The European city was located in the urban centre, well served with services and facilities, modern, and reserved for commerce; the Quilombola, besieged and forgotten, were located mainly on hills and reserved for the people who were expelled from the inner city, poor workers who consisted in their majority of black people; while the Suburban city comprised the neighbourhoods surrounding the city centre, and was intended for qualified workers who did not want to live on the hills [7]. 
In both the Quilombola and the Suburban cities a range of socioenvironmental problems were present, a scenario that tended to worsen from the 30 's until the 60's due to the arrival of newcomers. Favelas boomed at an average rate of $20 \%$, and spread over several downtown areas. Suburbs had an increment in their geographical area, in this way merging with the peripheral zones. Disgraced by the illegality present in their occupation process, peripheral areas did not receive any kind of investment.

In the 70s, a rearrangement of urban areas took place. The population living in Rio de Janeiro's central favelas was transferred to housing blocks located in the peripheral areas of the West Side and São Gonçalo. As a consequence, these locations experienced a population boom, which led to an intensification of the already existing problems. In the 80's and 90's urban violence took the stage, being related not only to drug dealing, but also to thievery, robbery, and murders. Such a reality is portrayed in the film City of God from 2002.

The economic crisis of the $80 \mathrm{~s}$, marked by high unemployment rates, overexploration of the workforce and the concentration of income to a small fraction of the population, contributed to the increment in extreme poverty in cities and large metropolises. Many people in this category were migrants from rural areas, e.g., the north-western areas of the state of Rio de Janeiro. Of a total of about 33 million extremely poor inhabitants, 35\% were found in cities and $41 \%$ in metropolises. Consequently, this poverty process reached the population in urban areas, through the peripheralization of the cities. of "urban edges", contributed t the outbreak of "exclusion agglomerations" in the following decades, nowadays called "risk cities". A century of urbanization, based on segregation and exclusion, determined the creation of the following types of cities:

Central City - well-located neighbourhoods that represent icons spread out all over through urban marketing. They are also called monument-cities, a consumer's dream for the top minority of the population. Each square meter of land is extremely expensive in such areas, once they are targeted by the real estate industry. Every day new construction sites arise and compelling facilities are added to them. Rio de Janeiro and Niterói are examples of central cities.

Encrusted between the icons, some favelas are to find. Although they are occupied by poor people, they, too, have experienced growth and are served with a wide range of services, provided mainly by NGOs.

Suburban City - neighbourhoods attached to the central city, provided with good services and infrastructure, and occupied by the lower middle class. Some of these areas have been renewed, thus provoking the creation of internal upperclass areas. There, favelas are also to find, although most of them were already occupied in the past.

Countryside Cities - are located outside the metropolitan area - cities in the north-western side of the estate are included in this group. 
Peripheral Cities - areas occupied in the 70s after the residents of favelas were expelled from urban areas. The West Side, São Gonçalo, and the Baixada Fluminense are key examples.

Risk Cities - most are situated at the edge of neighbourhoods, although they can also be found in central, suburban, and countryside areas. Their main characteristic consists of their location in risky zones: steep slopes, riverba The (de)generation process of these communities have provoked a number of unsustainable conditions that nowadays affect a considerable amount of people, and make them even more vulnerable to the recurrent hazard events [8, 9].

\section{Brazilian society and urban sustainability}

Brazilian cities, especially peripheral and risk cities, have faced considerable difficulties as regards the development of a just, democratic environment that is accessible to all. This scenario has thus been of great concern to Brazilian government and society. Such concern intensified in the 80's, given the aggravation of several problems, such as: lack of housing, poor transportation system, increase in the infant mortality rate due to diseases caused by the lack of sanitary services, epidemics, among others. As a result, this situation became part of the agenda of newer social movements that spread out within the redemocratization context of the country. The Federation Constitution promulgation in 1988 was, in this way, one of their milestones. A large social movement caused the new constitution to include a chapter about urban policies under the Economic Order title.

The development process of this policy was oriented towards the identification and analysis of the main urban problems: lack of housing, meagre services and urban infrastructure, poor transportation system, inadequate use of urban soil, lack of leisure sites, degradation of ecosystems as a result of illegal occupation, mainly by the real estate industry. These topics were discussed in nationwide forums, focusing on sustainability based on the socio-environmental function of urban ownership. The State was made responsible for the application of urbanism as a governmental function that should find in favour of all citizens, according to the principle of the fair distribution of benefits deriving from urbanization. In this way, it would become an intrinsic issue in the development of cities and their sustainability.

Social movements continued and in the year 2001 the Law 10.257 promulgated the so-called City Statute, which established the urban policy general guidelines. This law regulates the Articles 182 and 183 of the Constitution, demonstrates concern about the development of social functions of the cities, and assures the right to sustainable cities.

According to the Statute, urban policy aims to regulate the plain development of the social functions of cities and urban ownership by means of several guidelines. Among them, we can emphasize the following:

Assured right to sustainable cities, defined as the right to urban soil, housing, environmental sanitation, urban infrastructure, transportation, 
public services, labour, and leisure for the present and upcoming generations;

- Democratic management of cities, through the participation of the population and associations connected with the various social groups, in the formulation, execution, and follow-up of plans, programs, and projects related to urban development;

- Cooperation among governments, enterprises, and the other sectors of society with the urbanization process so as to meet the social interest;

- $\quad$ Planning the development and the spatial distribution of the population and the economic activities in cities and territories under their influence, aiming to prevent and review distortions in urban growth and the negative effects on the environment;

- $\quad$ Supply of urban and communitarian facilities, transportation and public services that are appropriate to the concerns and needs of the population and to local characteristics;

- $\quad$ Regulation and control over the use of soil;

- Integration and complementarity between urban and rural activities, focusing on the socioeconomic development of the city and the territory under its influence.

Municipal government is assigned responsibility for the urban policy through the employment of the following tools:

Some concepts raised by the City Statute are pointed out below:

The social function of ownership- public regulation's guiding principle on the right to urban ownership, aiming to ensure the right of the segregated, marginalized population to urbanized areas. It is related to the priority of group rights over the individual right to ownership in the formulation and implementation process of urban policies. It refers to the socially fair and environmentally sustainable use of urban areas. In addition, it comprises the governmental obligations regarding regulation and control over urban development, through territorial policies that aim to prioritize the social production of the environment, bearing in mind the prevalence of social, cultural, and environmental collective rights over the individual interests.

The social function of the city aims to assure the democratization of territories, and of authoritarian, productive, and cultural spaces, thus providing full access to the various functions of the city.

Society's concern for urban issues can also be observed in the Brazilian Agenda 21. It was launched with the participation of several segments of Brazilian society. One of its core aspects refers to the incorporation of two concepts, considered as key concepts within the scope of sustainable cities: amplified and progressive sustainability.

The concept of amplified sustainability describes sustainability as a pragmatic process of sustainable development. In turn, progressive sustainability introduces new dimensions to promote the understanding beyond economic and environmental matters, allowing sustainability to be conceived in accordance with the particularities present in each country or region. 
The Brazilian Agenda 21 points out sustainability criteria and vectors, as well as paradigms and products for sustainable development, with the aim of incorporating them into public, political, and private spheres. Within the context of the strategies mentioned, we emphasize the ones related to: sectional and spatial integration of urban policies and actions; strategic planning; decentralization; innovation incentives; environmental and social costs of economic and infrastructure projects; new consumer standards of urban services; and strengthening of the society and participation channels.

Besides incorporating several dimensions, the document suggests the disassociation between approach and confrontation of the social-environmental issue, by combining social development dynamics with dynamics related with the reduction of environmental impacts in urban areas.

At last, the Sustainable Cities Platform is considered. It was inspired in Aalborg Commitments(Denmark), a political treaty on sustainable development that has been already signed by more than 650 cities, mainly European ones. The commitment stake into account local community participation for decision taking, urban economy preservation of natural resources, social equality, the correct territorial regulation, urban mobility, world weather, biodiversity maintenance, among other relevant aspects. Due to the differences between Brazilian and European realities, two new topics were added to the Sustainable Cities Platform: Education for sustainability and quality of life, and culture for sustainability.

The platform, structured as an agenda of actions and initiatives, proposes a sustainable future for urban communities. In the ideal scenario, inclusive, wealthy, creative, educational, healthy, and democratic cities are created. Such cities promote a better quality of life for citizens and allow their participation in all issues concerning public life.

\section{Conclusions}

Overcoming elements of unsustainability present in cities in the RMRJ is not ensured by merely releasing documents, as they do not guarantee that changes will take place. They provide, however, certain guidance for the segments of society that are interested in taking part and attesting the fulfilment of the city's social function: guarantee territorial democratization, authoritarian spaces, production, and culture, thus enabling the access to all city functions. That is, by far, not our current reality, although we are aiming at this goal.

The advances made in urban sustainability issues to date can partly be attributed to contributions from public policies. The most significant is an innovative model in Latin America and its programmes and projects have contributed to significant changes in urban areas. The National Conference of Cities is one of the most important achievements of the Ministry. Since the first conference took place in Brasília in 2003, they have been held every two years, together with multiple sectors of society, in order to identify issues, and put forward proposals, relevant for achieving urban sustainability. One such proposal was the Bolsa Família Programme, an innovative social programme launched by 
the Brazilian government in 2003, that uses conditional cash transfers to incentivize children's schooling and supports family farming. Its implementation is the outcome of a partnership between the municipalities and the federal government.

The construction of Universities and enterprises in the construction of sustainable cities are now the subject of further research. University outré programmes, the topic of the forthcoming paper, have contributed to the application of the new tools produced in several ways. Firstly, this stimulates the participation of university entities in the development and promotion of public policies oriented to the majority of the population, and in the permanent qualification and education of decision-makers involved in social systems. Secondly, it provides new means and processes for the production, innovation, and transfer of knowledge, thus broadening the country's access to education and to technological and social development. Such initiatives have encouraged the establishment of partnerships based on sustainability-oriented units.

Enterprises, through the concept of Social Responsibility, and NGOs, by means of projects, have been directly acting towards initiatives that meet vulnerable communities. Universities, the governmental sector, enterprises, and NGOs have, individually, played key roles in the pursuit of sustainability issues in Brazil. This study indicates however, that partnership among them could lead to more effective contributions. Consequently, the participants in Environment, Sustainability and Social Responsibility research have been seeking alternatives to promote the establishment of partnerships between the different stakeholders.

\section{References}

[1] Sachs, I. Caminhos para o desenvolvimento sustentável.org. Paula Yone Stroh. Rio de Janeiro: Garamond, 2002.

[2] Boff, L. Saber cuidar: ética do humano - compaixão pela terra. Petrópolis. RJ: Vozes. 1999.

[3] Pochmann, M. and Amorim, R. A exclusão social no Brasil. São Paulo: Cortez. 2003.

[4] Bidone, E. D. and Morales, P. R. D. Introdução a noção de desenvolvimento sustentável In: Desenvolvimento sustentável e engenharia. Rio de Janeiro: Fundação Ricardo Franco, 2004. p.17-34.

[5] Castells, M. A. Questão urbana. Rio de Janeiro: Paz e Terra. 1983.

[6] Cassab, M. A .T. Young Poor Persons and the Future: the Construction of the Subjectivity in the Instability and Uncertainty. Niterói: Intertexto, 2001.

[7] Abreu, M. A evolução urbana do Rio de Janeiro. Rio de Janeiro: Zahar, 1988.

[8] Brazil, L. Urban Areas Segregated and Citizenship of the child: A proposal Educative of Formation for the Social Participation. Rio de Janeiro: Federal University of Rio de Janeiro, Institute of Psychology, 2003.

[9] Wacquant, L J. D. The condemned of the city. Novos Estudos CEBRAP, n.43, p.64-86, 1995. 